\title{
O Sistema de Organização Modular de Ensino (SOME) na ótica de egressos no município de Breves - Pará
}

João Marcelino Pantoja Rodrigues ${ }^{1}$, Gilmar Pereira da Silva ${ }^{2}$

${ }^{1}$ Universidade Federal do Pará - UFPA. Programa de Pós-Graduação em Educação. Campus Universitário do Marajó - Breves. Alameda IV, 3418, Parque Universitário, Breves - PA. Brasil. joaompr@ufpa.br. ${ }^{2}$ Universidade Federal do Pará - UFPA.

RESUMO. O presente trabalho é resultante de pesquisa em educação que analisa, a partir das percepções de egressos do ensino médio, as contribuições e limitações do Sistema de Organização Modular de Ensino (SOME) na formação educacional de jovens do campo no município de Breves, na Ilha do Marajó/Pará, perante as necessidades e expectativas desse público. A pesquisa se realizou por meio de um estudo de campo tomando como referência o materialismo históricodialético, sendo referenciado pela abordagem qualitativa na vila Mainardi, comunidade pioneira na oferta do SOME no meio rural brevense. Como principal técnica de coleta de dados utilizou-se a entrevista semiestruturada com seis jovens egressos, cujas respostas foram tratadas à luz da análise de conteúdo. Os resultados apontam para a afirmação da importância do SOME como única alternativa de acesso ao ensino médio para grande parcela dos jovens do campo paraense e, ao mesmo tempo, revelam o descompasso da experiência "somista" em relação às necessidades e expectativas desse público quanto ao ensino médio.

Palavras-chave: Sistema de Organização Modular de Ensino, Ensino Médio, Juventude do Campo. 


\title{
The Modular Teaching Organization System (MTOS) from the perspective of graduates in the municipality of Breves - Pará
}

\begin{abstract}
This work is the result of a research in education. It analyzes contributions and limitations of the Modular Teaching Organization System in the education of young people in the rural environment of the municipality of Breves, Pará, from the perceptions of high school graduates. It considers the needs and expectations of this public. The research was carried out through a qualitative field study in the Mainardi village, a pioneer community in the offering of this program in the rural environment of Breves. The main technique of data collection is a semi-structured interview with six young graduates, whose responses were treated in light of the thematic content analysis. The results point to the affirmation of the importance of this program as the only alternative of access to secondary education for a large portion of young people from the rural environment of Pará. At the same time, the results reveal the mismatch of the experience in relation to the needs and expectations of this public of secondary education.
\end{abstract}

Keywords: Modular Teaching Organization System, High School, Rural Youth. 


\section{El Sistema de Organización Modular de Enseñanza (SOME) en la óptica de egresados en el municipio de Breves - Pará}

RESUMEN. El trabajo es resultado de la investigación en educación analiza, a partir de las percepciones de egresados de la enseñanza media, contribuciones y limitaciones del Sistema de Organización Modular de Enseñanza (SOME) en la formación educativa de jóvenes del medio Rural del municipio de Breves - Pará, ante las necesidades y expectativas de ese público. La investigación se realizó por medio de un estudio de campo de base cualitativa en la villa Mainardi, comunidad pionera en la oferta del SOME en este medio rural. Como principal técnica de recolección de datos se utilizó la entrevista semiestructurada con seis jóvenes, cuyas respuestas fueron tratadas a la luz del análisis de contenido temático. Los resultados apuntan a la afirmación de la importancia del SOME como única alternativa de acceso a la enseñanza media para gran parte de los jóvenes del campo paraense y al mismo tiempo revelan el descompás de la experiencia 'somista' en relación a las necesidades y expectativas de ese público en cuanto a la enseñanza media.

Palabras clave: Sistema de Organización Modular de Enseñanza, Enseñanza Media, Juventud del Campo. 


\section{Introdução}

O Sistema de Organização Modular de Ensino (SOME) é uma política educacional estabelecida no estado do Pará no princípio da década de 1980, com o intuito de levar a educação pública, especialmente o ensino médio, às populações do interior não atendidas pela oferta regular.

O foco de nossa inquietação se volta para os jovens egressos ${ }^{\mathrm{i}}$ desse sistema no ensino médio no município de Breves, mais especificamente na Vila Mainardi, localidade pioneira de tal oferta no meio rural brevense, e que constituiu o lócus da pesquisa. A partir da ótica desses sujeitos, buscamos compreender e analisar as contribuições e limitações do processo formativo do ensino médio experienciado no SOME.

O crescimento da oferta educacional no âmbito do sistema modular, ao longo das três últimas décadas, é evidenciado em dados oficiais, como o "Mapa Exclusão Social do Estado do Pará 2017” (Fundação Amazônia de Amparo a Estudos e Pesquisas [Fapespa], 2017, p. 33), que registra a presença do SOME em quatrocentas e sessenta e cinco localidades do Estado, atendendo a trinta e seis mil alunos, o que nos dá uma dimensão do seu alcance nos dias atuais.
Ao longo desse período, o SOME tem acumulado êxitos, por um lado - ao alcançar parcelas da população que dificilmente seriam atendidas pela oferta regular -, e dilemas, por outro, ao não solucionar problemas crônicos que têm se reproduzido desde os primórdios do sistema, como a questão infraestrutural e organizativa.

Embora a política tenha sido implantada, em seus primórdios, nas sedes urbanas de alguns municípios do interior, como Nova Timboteua e Igarapé-Miri (Oliveira, 2010a), foi no meio rural que se expandiu e se consolidou nas últimas décadas em território paraense.

Sua regulamentação ocorreu no mês de abril de 2014, quando foi sancionada a Lei Estadual $n^{\circ}$. 7.806, conhecida entre os profissionais da área como "Lei do SOME", que dispõe sobre sua regulamentação e funcionamento. Embora esse dispositivo legal não seja o foco de nossa preocupação neste trabalho, acreditamos que ele não deve deixar de ser mencionado nas reflexões sobre o sistema modular, por se tratar de um documento norteador de referência legal no que tange a esse sistema.

A expansão progressiva da política e sua importância estratégica no âmbito educacional paraense tem despertado a atenção de pesquisadores como Oliveira (2010b), Queiroz (2010), Brayner (2013) e 
Silva, Barros e Oliveira (2014), para citar alguns, que passaram a se debruçar sobre a temática e levaram a discussão ao meio acadêmico. Todavia, apesar desse esforço, percebemos que a produção em torno da questão é ainda incipiente, ensejando a continuidade e a ampliação das pesquisas, com a diversificação dos ângulos de análise.

Foi pensando nesta incipiência e, ao mesmo tempo, na necessidade de ampliação dos estudos, bem como na relevância social e acadêmica da temática, justificada pelo expressivo alcance da política em nível estadual desde que surgiu, que nos propusemos a problematizar: como os jovens egressos do SOME na vila Mainardi, meio rural do município de Breves, na Ilha do Marajó, percebem o Sistema de Organização Modular de Ensino quanto às contribuições e limitações dessa política à sua formação no ensino médio, tendo como referência as necessidades e expectativas dessa juventude?

Partindo dessa inquietação, definimos o seguinte objetivo geral para o estudo: analisar, a partir da ótica de egressos do ensino médio da Vila Mainardi, as contribuições e as limitações do Sistema de Organização Modular de Ensino (SOME) na formação educacional de jovens do meio rural do município de Breves na Ilha do Marajó, no estado do
Pará, perante as necessidades e as expectativas dessa população jovem.

Assim, considerando o foco do problema e o objetivo pretendido com a investigação, estabelecemos alguns eixos teóricos que consideramos basilares a uma análise mais sistêmica do objeto, quais sejam: Sistema de Organização Modular de Ensino, Ensino Médio, Juventude (e, em particular, Juventude do Campo) e Educação do Campo. Tais eixos nos serviram de guias teóricos para a condução das fases seguintes do estudo.

\section{Caracterização da pesquisa}

Considerando a natureza do objeto e a configuração do problema de pesquisa sobre o qual nos debruçamos, e ainda com base nas contribuições teóricas de Gil (2002), entendemos o estudo de campo como a estratégia mais adequada a esta empreitada, uma vez que focaliza uma comunidade geográfica que pode ser uma comunidade de trabalho, de estudo, de lazer, ou ainda voltada para qualquer atividade humana.

A partir dessa conceituação, e num esforço de aproximação metodológica, trazemos ao plano de nossa análise a Vila Mainardi - primeira localidade a ofertar turmas do SOME no meio rural brevense, fato ocorrido em março de 2008 com o funcionamento de uma turma de $1^{\circ}$ ano do 
ensino médio na Escola Municipal de Ensino Fundamental Ivo Mainardi. Dos quarenta alunos que iniciaram as atividades naquela ocasião, dezoito se formaram no ano de 2010. Até o início do ano de 2015, doze turmas haviam sido formadas no ensino médio no meio rural de Breves ${ }^{\mathrm{ii}}$ por intermédio desse sistema.

Ampliando um pouco mais a contextualização de nosso objeto, é também pertinente justificarmos a escolha do município de Breves, no qual se situa a Vila Mainardi, tanto por sua indubitável condição de polo regional no Marajó quanto por ser a sede da $13^{\mathrm{a}}$ Unidade Regional de Educação - URE, da Secretaria de Estado de Educação SEDUC/ Pará, que responde, no Estado, pelas ações educacionais desenvolvidas na região, coordenando, além de Breves, outros oito municípios da região das ilhas: Anajás, Bagre, Curralinho, Portel, Melgaço, Gurupá, Chaves e Afuá. Assim, conjugando nosso objeto de inquietação com a análise empreendida por Gil (2002), nos convencemos de que a configuração contextual da Vila Mainardi, associada ao modo como pensamos o problema de pesquisa, constituiria terreno propício à implementação de um estudo de campo, como de fato o foi.

Nesse percurso, optamos pelo desenvolvimento de uma abordagem qualitativa ancorada nos pressupostos do materialismo histórico-dialético. Para tanto, referenciamo-nos na corrente que defende essa utilização conjunta, pela riqueza propositiva que traz ao método científico. Araújo (2012) destaca que em pesquisa social não é proibido ao marxismo assumir procedimentos próprios do chamado método qualitativo.

Com esse intuito, estabelecemos esse foco qualitativo com base em autores como Minayo (2013; 2014), buscando tomar os sujeitos da pesquisa em uma perspectiva dialética, constituídos de múltiplas determinações históricas, em relação dinâmica com o contexto contraditório no qual estão imersos: sujeitos, portanto, também contraditórios, também dialéticos, também históricos, e forjados na materialidade histórica de uma sociedade de classes.

Considerando o foco qualitativo que elegemos para a investigação, optamos pela entrevista semiestruturada como técnica principal de coleta de dados, utilizada junto a jovens egressos do ensino médio modular na Vila Mainardi, que designamos como "E1" (Entrevistado 1) até "E6". O tratamento e a interpretação do material obtido em campo realizaram-se por meio da análise de conteúdo temática com base, sobretudo, nas contribuições de Franco (2007) e Bardin (2011). Não obstante, também fizemos uso de observação e análise documental, mas 
como procedimentos acessórios para o fornecimento de elementos subsidiários a uma visualização mais detalhada do objeto.

\section{O "SOME" aparece e se expande: uma visão geral do sistema}

Conforme já destacado, o SOME surge com a finalidade de atender às comunidades do interior do Pará que não recebiam a oferta de ensino regular, particularmente o ensino médio. A partir de então, o sistema modular se expandiu exponencialmente pelo Estado, tornandose a principal política de oferta do ensino médio no campo, conforme aponta Oliveira (2010b, p. 18), "Este que fora pensado a princípio como medida transitória, passou a fazer parte indispensável do Sistema Estadual de Ensino e a única forma de estender o Ensino Médio às comunidades rurais, devido às grandes distâncias entre elas e à baixa densidade demográfica".

Com a Lei Estadual n ${ }^{\circ} 7.806$, de 29 de abril de 2014, o sistema passa a ser regulamentado como uma Política Pública Educacional do Estado do Pará, com uma intencionalidade expressa legalmente:

Art. $2^{\circ} \mathrm{O}$ Ensino Modular visa garantir aos alunos acesso à educação básica e isonomia nos direitos, assegurando a ampliação do nível de escolaridade e a permanência dos alunos em suas comunidades, observando as peculiaridades $\mathrm{e}$ diversidades encontradas no campo, águas, florestas e aldeias do Estado do Pará.

Parágrafo único. O Ensino Modular é direcionado à expansão das oportunidades educacionais em nível de ensino fundamental e médio para a população escolar do interior do Estado, onde não existir o ensino regular, de modo complementar ao ensino municipal. (Lei Estadual $\mathrm{n}^{\circ}$. 7.806, 2014.)

Como se observa, embora o nível médio seja o que constitui o atendimento preponderante do SOME, também o ensino fundamental é abrangido por este sistema. Contudo, esta própria Lei prevê o repasse do nível fundamental via SOME à responsabilidade das municipalidades, conforme segue:

Art. 18. A Secretaria de Estado de Educação, no prazo de até dezoito meses, a contar da publicação desta Lei, desenvolverá estudo, planejamento e reordenamento da oferta dos anos finais do ensino fundamental na modalidade do Sistema de Organização Modular de Ensino, visando transferir a gerência desses anos finais às prefeituras cujo ensino fundamental esteja municipalizado. (Lei Estadual $\mathrm{n}^{\circ}$. 7.806, 2014)

Isso implica dizer que essa política tende a se consolidar como de oferta unicamente de ensino médio. Assim, para o propósito desta pesquisa, preocupa-nos especificamente este nível de ensino por ser o preponderante no SOME.

Seu funcionamento ocorre com a composição de circuitos, que são assim 
conceituados pelo parágrafo $4^{\circ}$ do artigo $8^{\circ}$ da sobredita Lei: "Para fins desta Lei, denomina-se circuito o conjunto de localidades em que o professor deverá atuar durante o ano letivo, devendo na composição do mesmo priorizar o município e a URE em que o professor estiver lotado."
Cada circuito é composto por quatro localidades/ polos, nos quais os professores atuam em rodízio, ministrando os blocos de disciplinas ${ }^{\mathrm{iii}}$. A figura a seguir ilustra essa lógica:

Figura $1-\mathrm{O}$ circuito do SOME.

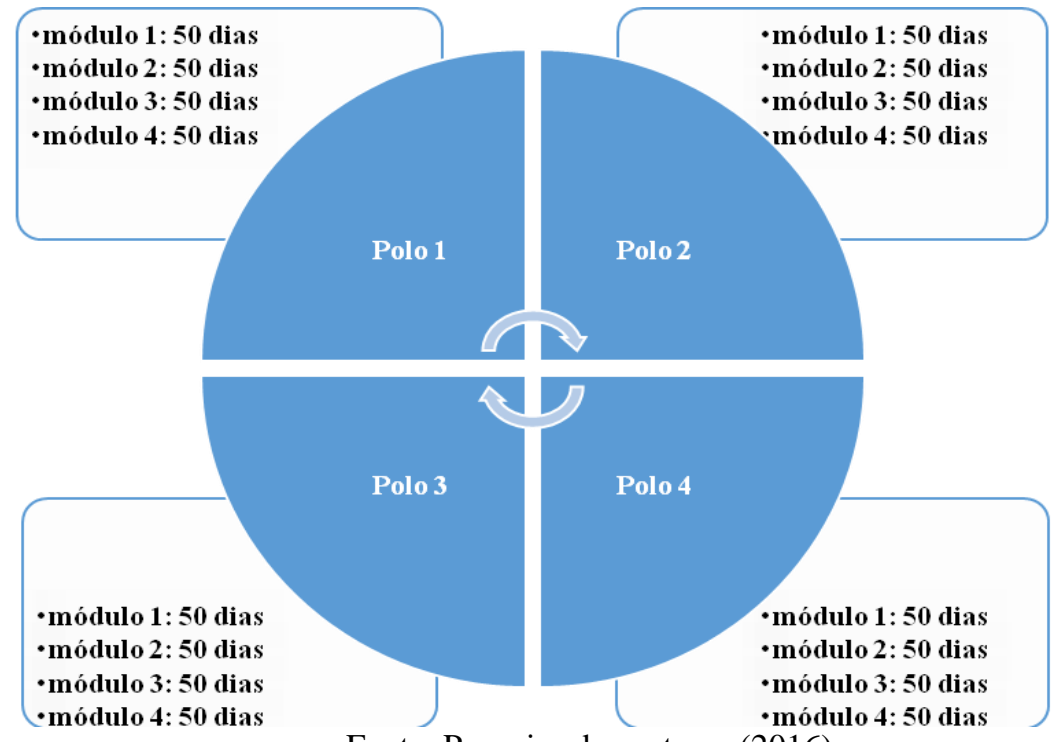

Fonte: Pesquisa dos autores (2016).

Os professores são lotados com jornada integral de 40 (quarenta) horas semanais, como define o caput do artigo $8^{\circ}$ da referida Lei, em consonância com o disposto no artigo 35 da Lei Estadual $n^{\circ}$ 7.442/2010 (Plano de Cargos, Carreira e Remuneração dos Profissionais da Educação Básica da Rede Pública de Ensino do Estado do Pará).

O parágrafo $3^{\circ}$ do artigo $8^{\circ}$ da Lei do SOME também estabelece que podem ser desenvolvidos projetos educacionais nas comunidades como forma de complementar a carga horária docente, conforme segue:

$\S 3^{\circ} \mathrm{O}$ professor lotado no SOME poderá complementar a carga horária de sala de aula com projetos educacionais na sua área de atuação, de modo a atingir a jornada de 40 (quarenta) horas semanais, quando a oferta de turmas não for suficiente para atingir o limite da carga horária em regência de classe da respectiva jornada. (Lei Estadual $\mathrm{n}^{\circ}$. 7.442, 2010) 
Como vemos, o desenvolvimento dos projetos pelos docentes nas comunidades, embora seja uma forma plausível de conferir um maior grau de materialidade aos conteúdos do ensino, não constitui uma dimensão efetivamente integrante $\mathrm{da}$ organização pedagógica do sistema modular, uma vez que sua implementação está diretamente condicionada a uma questão de complementaridade de carga horária.

O espaço de funcionamento do SOME nas comunidades rurais do Estado é, por sua vez e em geral, constituído de salas de escolas municipais que são cedidas para as turmas modulares, nos horários em que estão ociosas, sendo denominadas "Escolas Polo". Contudo, inexiste uma equipe gestora específica do sistema modular nas localidades de funcionamento. Assim, embora os alunos estudem em sua comunidade (ou em áreas vizinhas), são vinculados a uma "Escola Sede", situada na cidade e responsável pelo atendimento das demandas pedagógicoadministrativas em conjunto com as Unidades Regionais de Educação. A figura a seguir ilustra essa lógica de organização do sistema:

Figura 2 - Organização pedagógico-administrativa do SOME
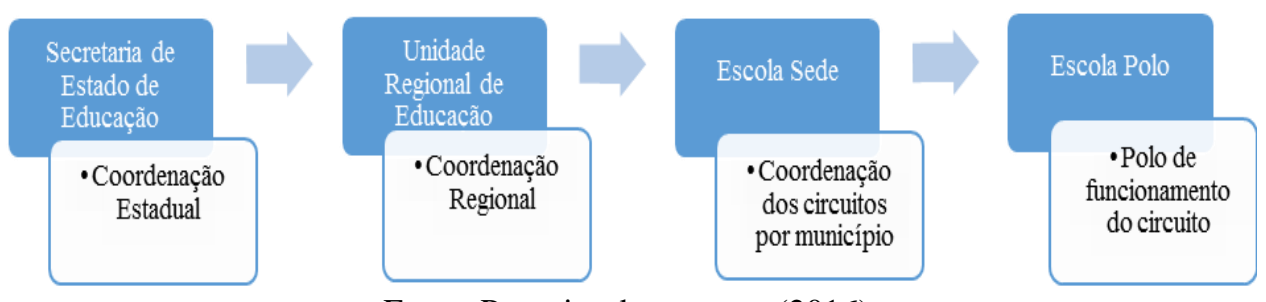

Fonte: Pesquisa dos autores (2016).

Para a manutenção do sistema é celebrado um Convênio de Cooperação Técnica entre a Secretaria de Estado de Educação do Pará e os municípios, conforme disposto no artigo 17 da Lei do SOME. E eis aí um dos imbróglios que perpassam seu funcionamento, visto que, não raro, os governos municipais argumentam (mesmo depois da assinatura do convênio) que tal atribuição é de competência prioritária do governo estadual, ao passo que o governo estadual alega que, sem a contribuição das municipalidades, não há como chegar às localidades mais longínquas do meio rural paraense.

A Lei ${ }^{\circ}$. 9394/1996, ao estabelecer as competências da esfera municipal no âmbito da oferta educacional, assim dispõe: 
Art. 11. Os municípios incumbir-seão de:

$\mathrm{V}$ - oferecer a educação infantil em creches e pré-escolas, e, com prioridade, o ensino fundamental, permitida a atuação em outros níveis de ensino somente quando estiverem atendidas plenamente as necessidades de sua área de competência e com recursos acima dos percentuais mínimos vinculados pela Constituição Federal à manutenção e desenvolvimento do ensino. (Lei $\mathrm{n}^{\mathrm{o}}$. 9.394, 1996).

Todavia, sem deixar de considerar os respectivos âmbitos de competência estabelecidos legalmente, entendemos que o adequado funcionamento do SOME, pela complexidade que envolve sua implementação, exige uma atenção interfederativa que concorra para a materialização do regime de colaboração, também amparado pelos mesmos instrumentos legais ora citados.

\section{A ótica dos egressos sobre o Sistema de Organização Modular de Ensino}

O exercício de sistematização e categorização do material das entrevistas, considerando nossas opções medotológicas, permitiu a emergência de um conjunto de categorias que Minayo (2014, p. 178) denomina de "empíricas", que são aquelas "construídas a posteriori, a partir da compreensão do ponto de vista dos atores sociais, possibilitando desvendar relações específicas do grupo em questão".

Com base em Bardin (2011, p. 134), buscamos a codificação do material oriundo das entrevistas, extraindo as unidades de registro, que são unidades de significação codificada e correspondem ao segmento de conteúdo considerado unidade de base, visando à categorização e à contagem frequencial. Deste esforço, procedemos às inferências por intermédio das quais chegamos aos agrupamentos categoriais, conforme quadro a seguir:

Quadro 1: demonstrativo de análise de conteúdo temática de entrevista semiestruturada.

\begin{tabular}{|l|c|c|}
\hline Unidades de registro & Subcategorias empíricas & Categorias empíricas \\
\hline & \multicolumn{2}{|c|}{ Fonte: Pesquisa dos autores (2016). }
\end{tabular}

Não obstante, convém enfatizar que essa estratégia não implica uma compartimentação estática da análise, pois temos clara a recomendação de Minayo (2013, p. 27) a qual corroboramos:
O tratamento do material nos conduz a uma busca da lógica peculiar interna do grupo que estamos analisando, sendo esta a construção fundamental do pesquisador. Ou seja, análise qualitativa não é uma mera classificação de opiniões dos informantes, é muito mais. É a descoberta de seus códigos sociais a 
partir das falas, símbolos e observações. A busca da compreensão e da interpretação à luz da teoria aporta uma contribuição singular e contextualizada do pesquisador.

Com esse cuidado, para o qual o materialismo histórico-dialético também se mostra essencial, buscamos a interlocução do rico material empírico com as discussões teóricas levantadas ao longo da empreitada. E, desse plano analítico, têmse os principais resultados da pesquisa, apresentados nos subtópicos seguintes.

\section{Se o professor "SOME": o descumprimento do calendário escolar}

Destacamos como primeira categoria empírica aquela que emergiu de modo mais incisivo, perpassando as falas de todos os entrevistados. Procedemos à identificação e ao isolamento das unidades de registro, com seu posterior agrupamento em conjuntos, conforme íamos identificando um determinado padrão nas respostas. Percebemos que os dados apontavam para uma insatisfação em relação à garantia do cumprimento dos módulos em consonância com o calendário escolar, constatação manifesta em duas distintas situações, a que denominamos subcategorias empíricas. Tais subcategorias apontavam para um conjunto maior, que veio a constituir a categoria empírica, conforme exemplificado no quadro a seguir:

Quadro 2 - Descumprimento do calendário escolar.

\begin{tabular}{|l|c|c|}
\hline \multicolumn{1}{|c|}{ Unidades de registro } & Subcategorias empíricas & Categoria empírica \\
\hline "Esse último que foi a gente tava \\
quase dois meses sem professor. E \\
$\begin{array}{l}\text { ano retrasado nós terminamos em } \\
\text { abril o ano de 2014 e ano de } 2015\end{array}$ & \\
não se sabe quando vai terminar. & & \\
$\begin{array}{l}\text { Acho que férias a gente tem todo } \\
\text { tempo. A gente fica mais de férias } \\
\text { do que estuda." (E6) }\end{array}$ & recorrência de longos intervalos & entre os módulos \\
\hline "Terminava os cinquenta dias, a \\
gente esperava uma semana, duas \\
semanas, vinha outro. Às vezes a \\
gente esperava até meses pra vim \\
um professor." (E3)
\end{tabular}

Fonte: Pesquisa dos autores (2016). 
O Quadro 2 apresenta um demonstrativo do que obtivemos em campo. O que observamos no conjunto das respostas é que o não cumprimento do calendário escolar se reflete tanto nos longos intervalos entre um módulo e outro - muito recorrentes pelo que se pôde depreender das falas - quanto dentro de um mesmo módulo, pelo não cumprimento dos cinquenta dias letivos por uma parcela dos professores.

É importante enfatizar que, embora essa insatisfação seja evidente - não somente no conteúdo das falas em si, mas na maneira de colocá-lo, nas ênfases, expressões dos rostos, etc. - os egressos também não se eximiram, por outro lado, de elogiar o trabalho daqueles professores que se esforçavam em cumprir com a sua jornada. Contudo, a ausência desse comprometimento por parte de outros colegas de trabalho faz com que, em uma análise mais geral, se associe ao SOME uma visão negativa, nesse aspecto.

Esse achado converge com o resultado da pesquisa de Oliveira (2010b) realizada nos municípios de Santarém e Belterra, segundo a qual o cumprimento das datas estabelecidas no calendário escolar tem sido um ponto central das reivindicações dos alunos quando o tema é o SOME.

Depreendemos, a partir de tais constatações, ser o descumprimento do calendário escolar uma das grandes limitações do SOME. É evidente que, se no percurso formativo do aluno o sistema demonstra dificuldades em garantir um mínimo necessário dos conteúdos de ensino, mais gritante ainda são essas dificuldades se considerarmos a necessidade de uma formação sob a perspectiva unitária, que aqui defendemos como condição para a formação integral do indivíduo e que tem Antônio Gramsci como um de seus grandes expoentes. É ancorado neste autor, e mais especificamente em seu "Caderno 12, Os intelectuais e o princípio educativo", que Nosella (2011) busca aquilo que denomina de "princípio pedagógico próprio do ensino médio":

A última fase da escola unitária (ensino médio) deve ser concebida e organizada como fase decisiva, na qual se tende a criar os valores fundamentais do 'humanismo', a autodisciplina intelectual e a autonomia moral necessárias a uma posterior especialização, seja ela de caráter científico (estudos universitários), seja de caráter imediatamente prático-produtivo (indústria, burocracia, comércio etc.). $\mathrm{O}$ estudo e o aprendizado dos métodos criativos na ciência e na vida devem começar nesta última fase da escola. (Gramsciv ${ }^{\text {iv }}$, 2000, p. 39, apud Nosella, 2011, p. 1060).

Ora, isso pressupõe, entre outras questões, a potencialização de uma ambiência efetivamente escolar ao sujeito, o que obviamente requer a garantia de 
regularidade no tempo escolar, e que também extrapole os limites da sala de aula e promova momentos de socialização com seus pares e com a comunidade a seu redor, contribuindo para a criação de atitudes e valores pautados em uma educação efetivamente cidadã. De certo, avaliando por esse prisma, não há dúvidas de que ainda temos muito a avançar, tanto no SOME quanto no próprio ensino regular.

\section{Se o aluno "SOME": o desafio da permanência escolar}

Também a questão da evasão escolar emergiu como limitação do sistema modular, decorrente da instabilidade na oferta dos módulos, apontada na categoria anterior, bem como pela indisponibilidade do transporte escolar, e a oposição emprego $\mathrm{x}$ estudos para muitos jovens. Pudemos perceber que a instabilidade na oferta é desencadeadora de um processo de desmotivação que acaba ocasionando muitas desistências, conforme nos foi relatado. Já outros desistiam pela impossibilidade de conciliar os estudos com o emprego na iniciativa privada local.

Quadro 3 - Evasão escolar.

\begin{tabular}{|c|c|c|}
\hline Unidades de registro & Subcategorias empíricas & Categoria empírica \\
\hline $\begin{array}{l}\text { "A desmotivação, tristeza, era essa } \\
\text { da falta de professor." (E2) }\end{array}$ & \multirow{3}{*}{$\begin{array}{l}\text { Desmotivação discente decorrente } \\
\text { da instabilidade na oferta modular }\end{array}$} & \multirow{6}{*}{ Evasão escolar } \\
\hline $\begin{array}{l}\text { "falta de professor. Quando faltava } \\
\text { professor, a gente ia duas, três } \\
\text { vezes à noite lá e nunca tinha } \\
\text { professor e ninguém sabia dar } \\
\text { nenhuma informação pra gente. E } \\
\text { isso desmotivava." (E4) }\end{array}$ & & \\
\hline $\begin{array}{l}\text { "Muitas vezes é por isso que } \\
\text { muitos desistem, porque custa a ir } \\
\text { professor, e quando vai é rápido." } \\
\text { (E6) }\end{array}$ & & \\
\hline $\begin{array}{l}\text { "A dificuldade era da locomoção. } \\
\text { A gente tinha que batalhar. Eu } \\
\text { trabalhava não era pra comer, nem } \\
\text { vestir, era pra despesa só da } \\
\text { gasolina." (E2) }\end{array}$ & \multirow{2}{*}{$\begin{array}{l}\text { Indisponibilidade de transporte } \\
\text { escolar }\end{array}$} & \\
\hline $\begin{array}{l}\text { "Muitos não aguentavam por causa } \\
\text { do gasto que era muito grande, } \\
\text { todo dia gasolina. Muitos paravam } \\
\text { até no primeiro mês já." (E5) }\end{array}$ & & \\
\hline $\begin{array}{l}\text { "tem muitos pais de família, que } \\
\text { tem filho, tem mulher e precisam } \\
\text { do trabalho. E como eles precisam } \\
\text { mais do trabalho, eles optam pelo } \\
\text { trabalho." (E3) }\end{array}$ & Oposição emprego x estudos & \\
\hline
\end{tabular}




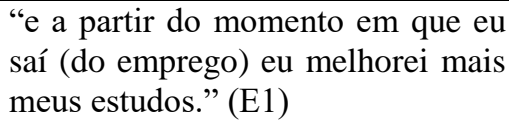

Fonte: Pesquisa dos autores (2016).

Tais constatações fazem mais sentido à medida que consideramos o contexto que delineia as condições de produção do conteúdo em questão. Assim, é importante compreendermos a Vila Mainardi como uma propriedade privada com três núcleos principais de produção: serraria, fábrica de gelo e indústria de beneficiamento de açaí em polpa para exportação. Tal situação nos remete ao que Marx e Engels, em A Ideologia Alemã (1988, p. 55-56), nos dizem a respeito da propriedade privada: "Ela é a expressão mais flagrante da subordinação do indivíduo à divisão do trabalho, a uma determinada atividade que lhe é imposta". No caso da Mainardi, percebemos que a relação de emprego estabelecida entre a empresa e os alunos trabalhadores do SOME se constitui como obstáculo ao desenvolvimento dos estudos no ensino médio. A lógica produtiva do setor privado local exige prontidão e disponibilidade do trabalhador para o cumprimento das metas de produção, não raro induzindo o aluno a ter de escolher entre trabalhar ou estudar.

Essa subordinação dos trabalhadores à divisão do trabalho trazia um elemento que a agudizava ainda mais: o fato de a moradia ser condicionada à relação de emprego, uma vez que as residências são de propriedade da empresa. Quando a relação empregatícia é desfeita, o exempregado deve entregar a moradia e sair do local. É o que destaca E3: "Lá quando tu sai, quando eles te mandam da empresa, tu tem que deixar a casa, porque quando tu sai provavelmente já tá entrando outro, aí a casa já vai pra quem já tá entrando... Lá tudo é cobrado". Com efeito, a manutenção do vínculo empregatício é também, para alguns, a única garantia (ainda que temporária) de um lugar para morar, o que torna a relação de dependência ainda mais brutal.

Assim, sem desconsiderar que haja outros desencadeadores do fenômeno da evasão na realidade estudada, para além dos que emergiram das falas dos sujeitos, parece-nos evidente que as características socioeconômicas dos alunos, com aquelas da localidade em questão e as do próprio funcionamento do sistema modular, compõem um conjunto oportuno à manifestação do fenômeno da evasão, que precisa ser levado em consideração no planejamento da política.

\section{O sentimento de inclusão/exclusão discente}


Outra categoria empírica emergente reflete o sentimento de inclusão/exclusão discente. $\mathrm{O}$ sentimento de exclusão parece compartilhado entre os entrevistados, particularmente no que se refere à organização do sistema, à (não) inserção dos discentes nas programações culturais da escola Ivo Mainardi e aos aspectos infraestruturais, caracterizando uma limitação do SOME também nesse sentido.

Ao longo da pesquisa de campo, foi revelador perceber o binômio “inclusão/exclusão" emergindo durante a fala de um mesmo sujeito: em geral, ao mesmo tempo em que se expunha o descontentamento com determinada situação, mencionando expressamente o termo "exclusão", ou subentendendo-o, em um conjunto maior, havia uma preocupação em mencionar momentos em que atitudes de inclusão, principalmente por parte de alguns professores, se faziam presentes como elemento catalizador de estímulo aos alunos.

Por essa razão, embora cientes da inviabilidade de uma análise conceitual mais pormenorizada dos termos "exclusão" e "inclusão" neste estudo, dados os objetivos e a delimitação da pesquisa, não poderíamos, por outro lado, deixar tais conceitos de fora de nosso plano analítico, visto que emergiram espontaneamente das falas dos sujeitos.

Assim, ao tratar de tais termos, procuramos ter em conta o alerta de autores como Oliveira (2000) e Ribeiro (2006) quanto aos cuidados necessários à utilização do conceito. Esta, por exemplo, ao tratar do termo "exclusão", afirma que este tem o mérito de ampliar a compreensão de problemas que fazem parte das relações sociais no modo de produção capitalista, mas que não podem ser explicados tão somente pela expropriação da terra ou pela apropriação do produto do trabalho, dos meios de produção e de sobrevivência. E, ao mesmo tempo, nos faz lembrar que:

É um conceito meramente descritivo e, como tal, tem alguma utilidade, entretanto apresenta-se como impessoal e neutro. Sem um adjetivo que o qualifique (social, escolar...), é abstrato, e para concretizar-se relaciona, de maneira contraditória, seres humanos posicionados como sujeitos que excluem, de um lado, ou como objetos que são excluídos, de outro. (Ribeiro, 2006, p. 158).

O quadro a seguir traz um demonstrativo do que emergiu da pesquisa em relação a esses aspectos: 


\begin{tabular}{|c|c|c|}
\hline Unidades de registro & Subcategorias empíricas & Categorias empíricas \\
\hline $\begin{array}{l}\text { "Aí bem dizer a gente era } \\
\text { excluído, sabe? Era só professor e } \\
\text { aluno, professor e aluno... O } \\
\text { diretor não dava muito apoio." } \\
\text { (E3) }\end{array}$ & $\begin{array}{c}\text { Sentimentos de inclusão/exclusão } \\
\text { associados à organização do } \\
\text { SOME }\end{array}$ & \multirow{4}{*}{ Sentimento de inclusão/exclusão } \\
\hline $\begin{array}{l}\text { "porque a gente falava que a } \\
\text { gente tinha direito, que a gente } \\
\text { era aluno, apesar de ser de outra } \\
\text { instituição, mas a gente era aluno } \\
\text { dali daquela localidade, sempre } \\
\text { foi." (E2) }\end{array}$ & $\begin{array}{c}\text { Sentimentos de inclusão/exclusão } \\
\text { associados à (não) inserção nas } \\
\text { programações culturais da escola } \\
\text { Ivo Mainardi }\end{array}$ & \\
\hline $\begin{array}{l}\text { "o diretor lá só cedia a escola, a } \\
\text { sala, né? Às vezes até a água } \\
\text { faltava." (E2) }\end{array}$ & \multirow[b]{2}{*}{$\begin{array}{c}\text { Sentimentos de inclusão/exclusão } \\
\text { associados à inadequação } \\
\text { infraestrutural }\end{array}$} & \\
\hline $\begin{array}{l}\text { "se a gente fosse pedir na } \\
\text { secretaria do fundamental, a } \\
\text { coordenação de lá ficava } \\
\text { reclamando 'esse papel não é pra } \\
\text { vocês, é pro fundamental', jogava } \\
\text { na cara, né? Aí tem que melhorar } \\
\text { isso." (E1) }\end{array}$ & & \\
\hline
\end{tabular}

Fonte: Pesquisa dos autores (2016).

Tais limitações, por sua vez, reforçam na realidade estudada a "situação de invisibilidade" constatada nos estudos de Weisheimer (2005), como característica dessa população juvenil residente no campo.

A "situação de invisibilidade" a que está sujeito esse segmento da população se configura numa das expressões mais cruéis de exclusão social, uma vez que dessa forma esses jovens não se tornam sujeitos de direitos sociais e alvos de políticas públicas, inviabilizando o rompimento da própria condição de exclusão. Nesse contexto, a juventude rural aparece como um setor extremamente fragilizado de nossa sociedade. Enquanto eles permanecerem invisíveis ao meio acadêmico e ao sistema político, não sendo socialmente reconhecidos como sujeitos de direitos, dificilmente serão incluídos na agenda governamental. (Weisheimer, 2005, p. 8)

A situação que, para o autor, se faz perceber particularmente no plano acadêmico e no político, encontra ressonância na problemática do SOME, ao analisarmos, por exemplo, a quantidade incipiente de trabalhos científicos sobre essa temática, bem como no político, ao analisarmos as limitações do sistema se reproduzindo há décadas, sem a implementação de iniciativas concretas que deem conta de sua resolutividade.

Por outro lado, a contradição da realidade nos mostra que, mesmo em meio a um ambiente desfavorável, é possível emergirem sentimentos de inclusão observados, por exemplo, no elogio dos 
entrevistados ao trabalho de alguns professores que, não obstante as dificuldades do sistema, se transformavam em motivadores dos alunos, fazendo-os persistirem na empreitada até o final. Ou ainda nos momentos em que a gestão da escola polo, mesmo tendo sua responsabilidade restrita ao ensino fundamental, buscava agregar também os alunos do SOME nos eventos culturais da escola, muito embora isso não ocorresse de modo sistemático. São situações como essas que contribuem para que o aluno siga em frente, conclua o ensino médio e alcance, por exemplo, o ingresso em um curso superior, configurando, ao mesmo tempo, uma dimensão contributiva do sistema para esse público jovem.

\section{A (in)adequação das práticas docentes à realidade do jovem do campo}

Outra limitação do SOME se refere à (in)adequação das práticas docentes à realidade do jovem do campo expressa, mediante a ótica dos egressos, no não esforço de alguns professores em contextualizar os conteúdos de ensino com as práticas sociais, focando o trabalho apenas no repasse de um conteúdo fragmentado. Tal limitação também se expressa na ausência de um trabalho sistemático com projetos educativos na localidade, o que a nosso ver poderia contribuir para uma maior interação do aluno com sua comunidade, conferindo um diferencial ao sistema modular. Não obstante, utilizamos o termo "(in)adequação" pelo fato de haver relatos, embora muito pontuais, que apontaram para a preocupação de alguns poucos docentes em potencializar a comunidade local como elemento referencial para suas práticas.

Quadro 5 - (In)adequação das práticas docentes à realidade do jovem do campo.

\begin{tabular}{|l|c|c|}
\hline \multicolumn{1}{|c|}{ Unidades de registro } & Subcategorias empíricas & Categorias empíricas \\
\hline "Tinha uns (professores) que não & & \\
olhavam o lado social, o lado que & & \\
se tá vivenciando, só explicavam \\
o conteúdo, mas teve uns que \\
sempre olhavam o lado da \\
$\begin{array}{l}\text { comunidade, sempre voltado na } \\
\text { realidade mesmo." (E2) }\end{array}$ & $\begin{array}{c}\text { (des)contextualização dos } \\
\text { conteúdos de ensino com as } \\
\text { práticas sociais }\end{array}$ & $\begin{array}{c}\text { (in)adequação das práticas } \\
\text { docentes à realidade do jovem } \\
\text { do campo }\end{array}$ \\
$\begin{array}{l}\text { mesmo. mais focado no conteúdo } \\
\text { preocupava. Queria só passar o }\end{array}$ & & \\
conteúdo." (E3) & & \\
\hline
\end{tabular}


"O único projeto que teve foi a feira de talentos. Nenhum outro professor fez... Durante eu estar estudando nenhum outro professor tinha feito um projeto." (E3) inexistência de um trabalho sistêmico com projetos educativos no SOME

Fonte: Pesquisa dos autores (2016).

As questões sintetizadas no Quadro 5 emergem como fatores contributivos à dificuldade de adequação das práticas dos professores do ensino modular à realidade do jovem do campo, refletindo uma limitação do SOME tanto com relação ao cumprimento das diretrizes nacionais do ensino médio quanto daquelas relacionadas à Educação do Campo:

Pois se trata de um modelo de ensino feito por módulos com pouca ou nenhuma articulação com as diretrizes da educação do campo. Consideramos ser um tipo de educação que ocorre no campo, todavia não existe capacitação aos professores a respeito da concepção filosófica que vem norteando a Educação do Campo, fazendo com que os professores desconheçam essa orientação tácita e teórica de que o que se deveria fazer nestas escolas seria uma modalidade de educação que valorizasse as práticas, a cultura, as condições geográficas dos jovens. (Silva, Barros \& Oliveira, 2014, p. 7).

À necessidade de uma formação adequada dos professores para trabalhar com essas distintas realidades se soma a de construção de uma proposta pedagógica para o sistema modular, posicionamento corroborado por Brayner (2013, p. 103). Entendemos que isso precisa ocorrer por intermédio de um processo democrático que ouça e contemple as expectativas do sujeito jovem do campo em relação ao ensino médio. Uma proposta que garanta a implementação de instrumentos democráticos de avaliação permanente do sistema como premissa do processo de planejamento.

\section{A inadequação do acompanhamento pedagógico e administrativo}

Ficou evidente, ainda, como limitação do sistema modular, a inadequação do acompanhamento pedagógico e administrativo, atinente ao distanciamento da coordenação pedagógica em relação aos polos e à fragilidade na comunicação entre as instâncias que constituem o sistema.

Quadro 6 - Inadequação do acompanhamento pedagógico e administrativo.

\begin{tabular}{|c|c|c|}
\hline Unidades de registro & Subcategorias empíricas & Categoria empírica \\
\hline $\begin{array}{l}\text { "Na verdade } \\
\text { acompanhamento pedagógico, } \\
\text { eles só iam lá quando acontecia } \\
\text { alguma coisa... "Ah, denunciaram }\end{array}$ & $\begin{array}{l}\text { distanciamento da coordenação } \\
\text { pedagógica em relação aos polos }\end{array}$ & $\begin{array}{c}\text { inadequação do } \\
\text { acompanhamento pedagógico e } \\
\text { administrativo }\end{array}$ \\
\hline
\end{tabular}

\begin{tabular}{|l|l|l|l|l|l|l|l|} 
Rev. Bras. Educ. Camp. & Tocantinópolis & v. 3 & n. 1 & p. $260-286$ & jan./abr. & 2018 & ISSN: 2525-4863 \\
\hline
\end{tabular} 


\begin{tabular}{|l|c|c|}
\hline $\begin{array}{l}\text { o professor porque ele fez tal } \\
\text { coisa', aí varavam pra lá pra } \\
\text { saber." (E3) }\end{array}$ & \\
\hline $\begin{array}{l}\text { "Ele (professor) deixou pra Belém } \\
\text { a nota. Aí quando esses alunos } \\
\text { que encerravam o ensino médio } \\
\text { vieram procurar pra poder fazer a } \\
\text { universidade tava lá pra Belém a } \\
\text { nota. Não tava nem na URE, nem } \\
\text { no MCP. E aí ele disse que não, } \\
\text { ele não deixou aí porque ele foi } \\
\text { contratado de lá de Belém, então } \\
\text { ele tinha que deixar lá." }\end{array}$ & $\begin{array}{c}\text { fragilidade na comunicação entre } \\
\text { as instâncias que constituem o }\end{array}$ & SOME \\
\hline
\end{tabular}

Fonte: Pesquisa dos autores (2016).

Tal achado reafirma o constatado no estudo de Silva, Barros e Oliveira (2014) que, ao tratarem do nível de improviso existente no processo de ensino modular, fazem referência à inadequação dos espaços onde as aulas são ministradas e à ausência de gestão dos espaços e do próprio processo pedagógico, uma vez que não há funcionários técnicos para atuar nas escolas.

Conclusão semelhante a esta é a de Oliveira (2010b, p. 105) que, em uma análise histórica dos elementos administrativos e pedagógicos do SOME, afirma:

Ficou confirmado que nunca existiu, desde a sua implantação, há cerca de trinta anos, acompanhamento pedagógico no SOME, exceto pelos dados sobre aprovação e média de notas dos alunos, suscitando preocupação constante quanto à ausência de instrumentos para o acompanhamento técnico-pedagógico e avaliativo do trabalho dos professores.

Isso evidencia que se trata de outro desafio a ser vencido para que o funcionamento do sistema ocorra de modo mais fluido e próximo do jovem do campo e de suas expectativas em relação ao ensino médio.

\section{O SOME e a função dual do ensino médio}

Ficaram evidenciados, nesse aspecto, elementos que apontam para as finalidades às quais tem servido o SOME, que, por seu turno, convergem para uma função dual do ensino médio, como categoria empírica, de acordo com o demonstrativo a seguir: 
Quadro 7 - Função dual do ensino médio.

\begin{tabular}{|l|c|c|}
\hline \multicolumn{1}{|c|}{ Unidades de registro } & Subcategorias empíricas & Categoria empírica \\
\hline $\begin{array}{l}\text { "Os alunos que entram no ensino } \\
\text { médio lá na Mainardi eles entram } \\
\text { só pra estudar mesmo e querer } \\
\text { terminar o ensino médio pra sair } \\
\text { pra trabalhar." (E1) }\end{array}$ & $\begin{array}{c}\text { SOME como meio de acesso } \\
\text { imediato ao mercado de trabalho }\end{array}$ & \multirow{2}{*}{ função dual do ensino médio } \\
\hline $\begin{array}{l}\text { "agora que eu fui aprovado nesse } \\
\text { curso (superior). Se não fosse } \\
\text { esse programa do SOME pra lá } \\
\text { não teria como." (E5) }\end{array}$ & $\begin{array}{c}\text { SOME como meio de acesso à } \\
\text { universidade }\end{array}$ & \\
\hline
\end{tabular}

Fonte: Pesquisa dos autores (2016).

Pudemos perceber que a função ora atribuída ao SOME remete à afirmação do dualismo que perpassa a história do ensino médio (Krawczyk, 2014; Nosella, 2015), que neste caso do sistema modular atende, com uma formação fragmentada, a um público da classe trabalhadora, cuja formação serve a uma perspectiva de acesso imediato a uma relação de trabalho assalariada junto à iniciativa privada local para atender às necessidades prementes de sobrevivência desse jovem. Por outro lado, essa formação também apresenta elementos que nos permitem visualizar a contradição, como por exemplo, no trabalho daqueles professores que demonstram compromisso com a formação humana e estimulam seus alunos a almejarem outros patamares de sociabilidade.

Nesse contexto, ao mesmo tempo em que para alguns egressos o SOME é a instância terminal dos estudos, é também notória a entrada de egressos do sistema no ensino superior como uma tendência emergente, particularmente da Vila Mainardi, sobretudo por sua relativa proximidade com a cidade, o que nos permite vislumbrar também aí a contradição. O meio que tem se mostrado mais favorável a esse ingresso é a educação a distância em faculdades privadas da cidade. Dos seis egressos entrevistados, quatro são universitários, dos quais três estudam nesta modalidade. Foi um posicionamento recorrente entre estes a afirmação de que, não fosse o SOME, dificilmente estariam hoje se graduando em uma universidade, pois não teriam condições de vir para a cidade cursar o ensino médio.

É bem verdade que o ingresso em um curso superior não necessariamente significa que os alunos terão maiores patamares de inserção social. Todavia, não se pode negar que, por meio desse acesso, se descortinam novas possibilidades que sequer poderiam ser sonhadas para alguns não fosse o sistema modular. 


\section{O SOME e a migração rural-urbana discente}

Foi perceptível uma possível relação do SOME com a questão da migração rural-urbana juvenil na realidade em questão. Tal constatação se deu ao ouvirmos egressos que, mesmo com a manifesta dificuldade de residir no meio urbano, vieram morar na cidade com a intenção de concluir o ensino médio na rede regular, dadas as dificuldades encontradas no SOME. E também ao ouvirmos outros que, ao concluírem o ensino médio no sistema modular, têm buscado a cidade para obter formação superior, o que certamente, neste caso, não significa uma negação da vida no meio rural, pois mesmo entre alguns destes foi enfática a afirmação de que pretendem retornar para contribuir com sua comunidade após a conclusão dos estudos.

Quadro 8 - Migração rural-urbana discente.

\begin{tabular}{|c|c|c|}
\hline Unidades de registro & Subcategorias empíricas & Categoria empírica \\
\hline $\begin{array}{l}\text { "No meu caso, como eu moro } \\
\text { aqui (na cidade), como eu tenho } \\
\text { opção, eu terminando o ensino } \\
\text { médio, vou procurar fazer curso." } \\
\text { (E1) }\end{array}$ & \multirow[b]{2}{*}{$\begin{array}{l}\text { Possibilidade de ida para a cidade } \\
\text { associada à disponibilidade de } \\
\text { mais recursos no meio urbano }\end{array}$} & \multirow{4}{*}{ Migração rural-urbana discente } \\
\hline $\begin{array}{l}\text { "seria mais fácil porque fica tudo } \\
\text { perto. Conhecimento, internet fica } \\
\text { perto, livros, seja o que você } \\
\text { quiser, em qualquer lugar, você } \\
\text { pode encontrar livros, comprar... } \\
\text { E lá (na Mainardi) não, tu ainda } \\
\text { tem que vir, tem que pesquisar, às } \\
\text { vezes não tem os recursos } \\
\text { adequados lá." (E3) }\end{array}$ & & \\
\hline $\begin{array}{l}\text { "tinha uns (colegas do SOME) } \\
\text { que falavam que se eles } \\
\text { arranjassem um trabalho fora, não } \\
\text { tinham vontade de voltar mais lá } \\
\text { não, só se fosse pra passeio } \\
\text { rápido. Sempre eu falava: "se for } \\
\text { pra repassar meus conhecimentos, } \\
\text { vai ser pras futuras gerações } \\
\text { daqui'." (E2) }\end{array}$ & \multirow{2}{*}{$\begin{array}{l}\text { Possibilidade de ficar no meio } \\
\text { rural associada à identidade com o } \\
\text { lugar de origem }\end{array}$} & \\
\hline $\begin{array}{l}\text { "eu já morei muito tempo lá (na } \\
\text { Mainardi)... Só que tem aquela } \\
\text { vontade de ir pra lá, porque foi lá } \\
\text { que eu cresci e de mostrar pras } \\
\text { outras pessoas, tipo ser espelho } \\
\text { das outras pessoas, sabe? Que um } \\
\text { dia eu fui que nem eles, eu fui } \\
\text { aluna e agora eu tô dando aula } \\
\text { lá." (E3) }\end{array}$ & & \\
\hline
\end{tabular}

Fonte: Pesquisa dos autores (2016). 
A situação em questão nos remete à "Carta Proposta da Juventude Trabalhadora Rural”, de março de 2015, que entende a migração juvenil como fenômeno complexo, fortemente condicionado aos aspectos sociais, econômicos e culturais estruturantes: "É preciso entender o êxodo rural não como escolha individual e privada, mas, articulado ao conjunto de oportunidades concretas vivenciadas pela juventude trabalhadora rural, no que se refere ao acesso a direitos e ao exercício pleno da sua cidadania." (Confederação Nacional dos Trabalhadores na Agricultura [CONTAG], 2015, p. 2). Desse modo, a perspectiva desse exercício pleno da cidadania parece em certa medida condicionada à ida para a cidade que, embora também não dê garantia concreta alguma, se mostra como uma opção mais viável ou, até, inevitável, em certos casos. Essa reafirmação de uma relação de dependência com a cidade é reforçada em um posicionamento teórico de Leão e Antunes-Rocha quanto à questão:

as limitações de acesso à educação e ao trabalho, e a questão fundiária têm levado os jovens a construir projetos de saída do campo em busca de melhores condições de vida. Por outro lado, isso não representa uma negação da vida no campo. Muitos jovens constroem projetos de saída, mas com perspectivas de retorno futuro. Outros mantêm trajetórias de idas e vindas entre o campo e a cidade. (Leão \& Antunes-Rocha, 2015, p. 23).

Certamente, não podemos, a partir dos exemplos citados, inferir generalizações de que o ingresso no ensino superior direcione necessariamente a uma perspectiva de retorno do egresso para desenvolver um trabalho em sua comunidade de origem. O que queremos é chamar atenção para o fato de que a experiência educativa no SOME abre condicionantes que interferem em maior ou menor grau nesse conflito da permanência ou saída do campo para o qual nos alertam os autores citados.

\section{Considerações finais}

Evidentemente, os resultados aqui apontados não pretendem - nem poderiam - dar conta da complexidade que perpassa o funcionamento de uma política pública que se espraiou nas últimas décadas pelas mais recônditas regiões do estado do Pará. Dada a delimitação estabelecida para esta investigação, é inevitável que haja muitas limitações no estudo, que ensejam a diversificação dos ângulos de análise por intermédio de novas investigações, para o que almejamos que outros pesquisadores se sensibilizem com a temática e se proponham a enriquecer a discussão.

De nossa parte, uma vez que nos propusemos a centrar o foco de nossa 
atenção no aluno, o principal interessado e a razão da existência da política em pauta, não nos é possível vislumbrar com exatidão, a partir da ótica da gestão do sistema ou, mesmo, dos docentes do SOME, possíveis condicionantes do que fora suscitado por nossos interlocutores. São, pois, aspectos que estão para além dos propósitos desta pesquisa, visto que requerem um estudo mais detido a partir de outros ângulos analíticos.

Assim, não temos por ora como estabelecer uma discussão quanto às reais causas da instabilidade na oferta dos módulos e, portanto, das dificuldades em garantir a devida sequência entre as disciplinas, sem longos intervalos. De igual modo, não podemos fazer uma análise comparada do fenômeno da evasão entre os sistemas regular e o modular de ensino, até mesmo pela dificuldade de se levantar dados estatísticos dessa natureza no SOME. Tampouco temos como visualizar as necessidades formativas ou motivações dos professores que atuam no sistema modular. Não obstante, estamos cientes, por um lado, de que limitações dessa natureza são próprias a qualquer tipo de pesquisa, dada a característica do inacabamento inerente ao próprio processo de construção do conhecimento e, por outro lado, cientes de que vislumbar o objeto a partir da ótica do público atendido foi uma experiência deveras enriquecedora e pertinente.

É preciso perceber, ainda, que o público jovem que demanda pelo ensino médio no meio rural brevense está espraiado por aproximadamente cento e setenta localidades do município, muitas delas de difícil acesso à sede do município, com deslocamento de mais de vinte e quatro horas de viagem via fluvial, que constitui o único acesso na região, conforme nos relata o Plano Municipal de Educação, aprovado pela Lei Municipal nº 2.388, de 2015. Destas localidades, apenas cinco são atendidas pelo SOME, o que nos chama a atenção para a ausência de políticas públicas para o atendimento desse contingente, bem como para uma maior capilaridade daquelas já existentes.

Em uma análise mais geral, de tudo o que fora exposto nas falas obtidas, notamos alguns aspectos que remetem aos achados de outras pesquisas realizadas sobre o SOME, particularmente os trabalhos de Queiroz (2010), Oliveira (2010b), Brayner (2013) e Silva, Barros e Oliveira (2014), mas que não se limitaram a isso.

Assim, com atenção à ótica dos sujeitos egressos, nossos interlocutores mas ao mesmo tempo colocando-a sob os pressupostos do materialismo históricodialético, que toma tais percepções como constructos, cujo cerne é a materialidade social, na qual os sujeitos se (re)fazem 
cotidianamente - e ao mesmo tempo com a triangulação em relação à experiência por nós obtida na coordenação regional da política no ano de 2009, e ao material teórico trazido para a presente discussão, nos foi possível perceber o sistema modular como uma política de afirmação e de negação concomitantes.

De afirmação, por promover a garantia do acesso à educação a parcelas significativas da população paraense; por permitir a um grupo cada vez maior de sujeitos a formação em um nível cuja realidade, há algum tempo, parecia utópica; por inscrever no âmbito de sua referência normativa legal, a Lei do SOME, a necessidade de uma formação que reconheça a(s) identidade(s) dos povos dos campos, águas e florestas. Mas de negação, ao não percebermos a concretude devida destes pressupostos na implementação do sistema, que deixa a desejar em infraestrutura, acompanhamento pedagógico, e em outros aspectos, configurando, em grande medida, a reprodução de um modelo educacional citadino no meio rural.

Ao mesmo tempo, percebemos a Vila Mainardi como uma totalidade, que em sua dinâmica reproduz a lógica capitalista vigente: a propriedade privada determinando uma divisão do trabalho que induz o jovem trabalhador/ estudante a uma formação suficiente para ingressar no mercado e atender a sua necessidade imediata de sobrevivência. Mas que é também contraditória, visto que um número crescente de egressos tem quebrado essa lógica e ingressado em um curso superior, vendo-se em condições de projetar novas perspectivas formativas.

Compreendemos também a Mainardi inserida em um contexto maior: o jovem trabalhador do campo, estudante do SOME, tem dificuldades específicas relacionadas ao sistema modular, mas é também um jovem da classe trabalhadora, que, assim como o da cidade, anseia por uma formação educacional e, junto a tantos outros jovens, sente e compartilha dificuldades oriundas da condição social que os une.

\section{Referências}

Araújo, R. M. L. (2012). O marxismo e a pesquisa qualitativa como referência para investigação sobre educação profissional. In Araujo, R. M. L., \& Rodrigues, D. (Orgs.). A Pesquisa em Trabalho, Educação e Políticas Públicas (pp. 157184). Campinas, SP: Alínea.

Bardin, L. (2011). Análise de conteúdo. São Paulo, SP: Edições 70. (Obra originalmente publicada em 1977).

Brayner, C. N. M. (2013). Um estudo avaliativo do Ensino Médio modular a partir das Diretrizes Operacionais da Educação Básica nas Escolas do Campo no Pará (Dissertação de Mestrado). Universidade do Estado do Pará, Pará. 
Confederação Nacional dos Trabalhadores na Agricultura - CONTAG (2015). Carta Proposta da Juventude Trabalhadora Rural. 2015. Recuperado de www.contag.org.br/imagens/f2330carta_iii festival_final-2.doc>

Ferreira, A. B. H. (2000). Miniaurélio Século XXI Escolar: o minidicionário da língua portuguesa. Rio de Janeiro: Nova Fronteira.

Franco, M. L. P. B. (2007). Análise de conteúdo. Brasília, DF: Líber Livro.

Gil, A. C. (2002). Como elaborar projetos de pesquisa. São Paulo, SP: Atlas.

Gramsci, A. (2000). Cadernos do Cárcere. Rio de Janeiro, RJ: Civilização Brasileira.

Fundação Amazônia de Amparo a Estudos e Pesquisas. (2017). Mapa Exclusão Social do Estado do Pará 2017. Recuperado de http://seplan.pa.gov.br/sites/default/files/P DF/loa/loa2018/mapa_de_exclusao_social _do_para_2017.pdf

Krawczyk, N. (2014). Uma roda de conversa sobre os desafios do ensino médio. In Dayrell, J., Carrano, P., \& Maia, L. M. (Orgs.). Juventude e ensino médio: sujeitos e currículo em diálogo (pp. 7598). Belo Horizonte, MG: editora UFMG.

Leão, G., \& Antunes-Rocha, M. I. (2015). Juventude no/do campo: questões para um debate. In Leão, G., \& Antunes-Rocha, M. I. (Orgs.). Juventudes do campo (17-27). Belo Horizonte, MG: Autêntica Editora.

Lei $n^{o} . \quad 9.394 / 1996 . \quad(1996,23$ de dezembro). Estabelece as Diretrizes e Bases da Educação Nacional. Recuperado de:

http://www.planalto.gov.br/ccivil_03/leis/L 9394.htm

Lei Estadual $n^{\circ}$ 7.442, de 2 de julho de 2010. (2010, 2 de julho). Dispõe sobre o
Plano de Cargos, Carreira e Remuneração dos Profissionais da Educação Básica da Rede Pública de Ensino do Estado do Pará e dá outras providências.

Lei Estadual $n^{\circ}$. 7.806, de 29 de abril de 2014. (2014, 29 de abril). Dispõe sobre a regulamentação e o funcionamento do Sistema de Organização Modular de Ensino - SOME, no âmbito da Secretaria de Estado de Educação - SEDUC, e dá outras providências. Diário Oficial do Estado do Pará. Belém, PA, 30 abr. 2014. Cad. 1 (pp. 5-6).

Lei Municipal $n^{\circ} 2.388$, de 24 de junho de 2015. (2015, 24 de junho). Aprova o Plano Municipal de Educação - PME e dá outras providências. Poder Público Municipal. Prefeitura Municipal de Breves. Recuperado de: http://simec.mec.gov.br/sase/sase_mapas.p $\underline{\text { hp? } \mathrm{uf}=\mathrm{PA} \& \text { tipoinfo }=1}$

Marx, K., \& Engels, F. (1988). A ideologia Alemã. São Paulo, SP: Martins Fontes. (Obra originalmente publicada em 1932).

Minayo, M. C. S. (2013). O desafio da pesquisa social. In Minayo, M. C. S. (Org.). Pesquisa Social: teoria, método e criatividade (9-29). Petrópolis, RJ: Vozes.

Minayo, M. C. S. (2014). O desafio do conhecimento: pesquisa qualitativa em saúde. São Paulo, SP: Hucitec Editora.

Nosella, P. (2011). Ensino médio: em busca do princípio pedagógico. Educ. Soc., 32(117), 1051-1066. DOI: http://dx.doi.org/10.1590/S0101$\underline{73302011000400009}$

Nosella, P. (2015). Ensino médio: unitário ou multiforme? Revista Brasileira de Educação, 20(60), 121-142. DOI: http://dx.doi.org/10.1590/S1413$\underline{24782015206007}$ 
Oliveira, A. R. (2000). Educação e exclusão: a contribuição da Filosofia da Educação na determinação conceptual. Perspectiva, 18(34), 11-31. DOI: https://doi.org/10.5007/\%25x

Oliveira, R. (2010a, 13 de julho). SOME: 30 anos de educação no campo [Blog]. Recuperado de: http://ribaprasempre.blogspot.com.br/2010/ 07/some-30-anos-de-educacao-nocampo.html

Oliveira, R. M. (2010b). Elementos administrativos e pedagógicos do SOME na percepção de seus autores (Dissertação de Mestrado). Universidade Católica de Brasília, Brasília.

Queiroz, A. G. (2010). O Sistema Modular de Ensino no Estado do Pará: contribuição para o desenvolvimento educacional no município de Abaetetuba (Dissertação de Mestrado). Universidade de Taubaté, Taubaté.

Ribeiro, M. (2006). Exclusão e educação social: conceitos em superfície e fundo. Educ. Soc., 27(94), 155-178. DOI: http://dx.doi.org/10.1590/S0101$\underline{73302006000100008 .}$.

Silva, G. P., Barros, O. F., \& Oliveira, V. B. (2014). Políticas de formação, currículo e trabalho para o ensino médio do campo na Amazônia: o Sistema de Organização Modular de Ensino - Some e sua atuação no município de Cametá-baixo Tocantins/PA. In XXII Encontro de Pesquisa Educacional do Norte Nordeste. EPENN, 28 a 31 de outubro de 2014, Natal, Brasil: Anais [Recurso Eletrônico] / Universidade Federal do Rio Grande do Norte. Centro de Educação. Programa de Pós-graduação em Educação. - Natal, RN.

Weisheimer, N. (2005). Estudos sobre os Jovens Rurais do Brasil: mapeando o debate acadêmico. Brasília, DF: Nead/ MDA.
1 O dicionário da língua portuguesa Aurélio (Ferreira, 2000, p. 251) define egresso como aquele "1. Que saiu, se afastou.". Para o efeito deste trabalho, consideramos como alunos egressos aqueles que: 1. Concluíram o ensino médio no SOME; 2. Evadiram; 3. Foram transferidos para outra unidade de ensino ou modalidade de oferta.

${ }^{2}$ Fonte: Escola Sede do SOME em Breves "Maria Câmara Paes". Jan. 2015.

3 Língua portuguesa, Educação Física, História, Geografia, Biologia, Física, Química, Matemática, Língua Estrangeira Moderna $\left(1^{\circ}, 2^{\circ}\right.$ e $3^{\circ}$ anos); Arte, Filosofia e Sociologia ( $1^{\circ}$ ano). Conforme o "Modelo Curricular para o Ensino Médio - Sistema Modular de Ensino", aprovado pela Resolução n ${ }^{\circ}$. 761/1998 CEE/Pará.

${ }^{4}$ Gramsci, A. (2000). Cadernos do Cárcere. Rio de Janeiro: Civilização Brasileira.

Recebido em: 22/11/2017 Aprovado em: 23/01/2018 Publicado em: 21/04/2018

Como citar este artigo / How to cite this article / Como citar este artículo:

APA:

Rodrigues, J. M. P., \& Silva, G. P. (2018). O Sistema de Organização Modular de Ensino (SOME) na ótica de egressos no município de Breves - Pará. Rev. Bras. Educ. Camp., 3(1), 260-286.

ABNT:

RODRIGUES, J. M. P.; SILVA, G. P. O Sistema de Organização Modular de Ensino (SOME) na ótica de egressos no município de Breves - Pará. Rev. Bras. Educ. Camp., Tocantinópolis, v. 3, n. 1, p. 260-286, 2018.

\section{ORCID}

João Marcelino Pantoja Rodrigues

http://orcid.org/0000-0001-8168-8596 
Gilmar Pereira da Silva

(iD http://orcid.org/0000-0001-9814-9089

Os autores declaram que foram responsáveis pela elaboração, análise e interpretação dos dados; escrita e revisão do conteúdo do manuscrito, bem como pela aprovação da versão final a ser publicada. 